\title{
Prevention of COVID-19: public health response at points of entry in Sri Lanka
}

\section{SM Arnold ${ }^{*}$, SD Samarasekera ${ }^{1}$, RPP Karunapema ${ }^{2}$, HMRC Samath ${ }^{1}$, TLC Somatunga ${ }^{3}$, Paba Palihawadana $^{3}$}

${ }^{1}$ Quarantine Unit, Ministry of Health, Sri Lanka; ${ }^{2}$ Health Promotion Bureau, Ministry of Health, Sri Lanka; ${ }^{3}$ Ministry of Health, Sri Lanka

"Correspondence: mahendra_arnold@yahoo.com

iDhttps://orcid.org/0000-0001-7746-8515

DOI: https://doi.org/10.4038/jccpsl.v26i5.8330

Received on 14 May 2020

Accepted on 5 June 2020

\section{Summary}

The news that an unknown virus is causing pneumonia in people in Wuhan City of China was circulated in media in late 2019 (1-3). A novel coronavirus was identified on 7 January 2020 (4). The city of Wuhan was placed in quarantine on 23 January 2020. The quarantine was later extended to a further 17 cities in Hubei Province, affecting over 57 million people (5-6).

The first case of Coronavirus disease - 2019 (COVID-19) outside China was reported in Thailand on 13 January 2020 (7). The WHO declared novel coronavirus outbreak as a Public Health Emergency of International Concern (PHEIC) on 30 January 2020 (8). On 11 March 2020, considering the alarming levels of spread and severity, the WHO categorized COVID-19 as a pandemic (9). This narrative report highlights the public health measures taken at points of entry to prevent COVID-19 in Sri Lanka.

\section{Public health response and its impact}

\section{Goal to be achieved}

Sri Lanka was considered a high risk country for the introduction of the disease due to being an international tourist destination and having a considerable number of Chinese workers employed in mega projects and Sri Lankan migrant workers working in countries where there was rapid disease spread. Hence, the main goal was to prevent the introduction of COVID-19 to the country. With this goal, many public health measures were applied at points of entry.

\section{Points of entry}

Sri Lanka has four airports (Katunayake, Mattala, Jaffna and Ratmalana) and five seaports (Colombo, Galle, Hambantota, Trincomalee, Norochcholai), 
which function as points of entry (POE) for international travellers to Sri Lanka. Of these, Katunayake Bandaranaike International Airport (BIA) and Colombo Port are designated points of entry under the International Health Regulations (IHR)-2005. All the airport and port health offices in points of entry are under the Quarantine Unit of the Ministry of Health. In Sri Lanka, Co-National Focal Points of IHR-2005 are the Quarantine Unit and Epidemiology Unit. The Quarantine Unit has the responsibility to prevent the introduction of COVID-19 to Sri Lanka through these points of entry.

\section{Public health response}

Following public health response measures were applied:

- Temperature screening of travellers entering Sri Lanka

- Screening of passengers through data obtained from the Health Declaration Form

- Transferring suspected COVID-19 passengers to treatment centers

- Conducting awareness programmes for airport and port staff

- Development and dissemination of IEC material on prevention of COVID-19 to passengers in the form of information sheets, leaflets, banners and videos

- Awareness of general public through mass media

- Compiling data and community follow-up

- Quarantining passengers

- Travel restrictions and closure of airport for inbound flights

\section{Stakeholder sensitization and initial preparation}

Sri Lanka, initiated measures to prevent introduction of COVID-19 at an early stage of the epidemic. A vast majority of travellers enter into the country through the BIA and measures were taken initially to strengthen the on-site preventive measures as per National Public Health Contingency Plan for Designated Airports in Sri Lanka. Many stakeholders work in liaison to provide services at the airport. Introduction of any measure involving passengers needs the concurrence as well as the support of the key stakeholders.

As the health sector, Quarantine Unit of the Ministry of Health took the lead role and prepared a plan of action to prevent introduction of COVID-19 disease from the main airport. The action plan was discussed with all relevant authorities at a meeting chaired by the Deputy Director General (Public Health Services)- 1 held on 21 January 2020 and the contingency plan was activated. Rapid assessment of IHR core capacities for the POEs was conducted. The identified gaps were rectified.

\section{Public health measures and difficulties faced}

\section{a. Awareness of passengers and staff}

Travelers were educated through announcements in the flights, video clips displayed in the flights and the airport, display banners and leaflets containing information about the disease, preventive measures and available health services. Such educational material was developed in collaboration with the Health Promotion Bureau.

Making the airport staff aware of the preventive measures was done through several awareness programmes to the staff of the Sri Lankan Airlines, ground handling staff, security officers, custom officers and immigration officers who came in direct contact with passengers (Figure 1).

The general public was made aware of disease prevention and control by the Quarantine Unit through various programmes conducted in mass media. These included discussions in various television channels, radio channels and newspapers. 


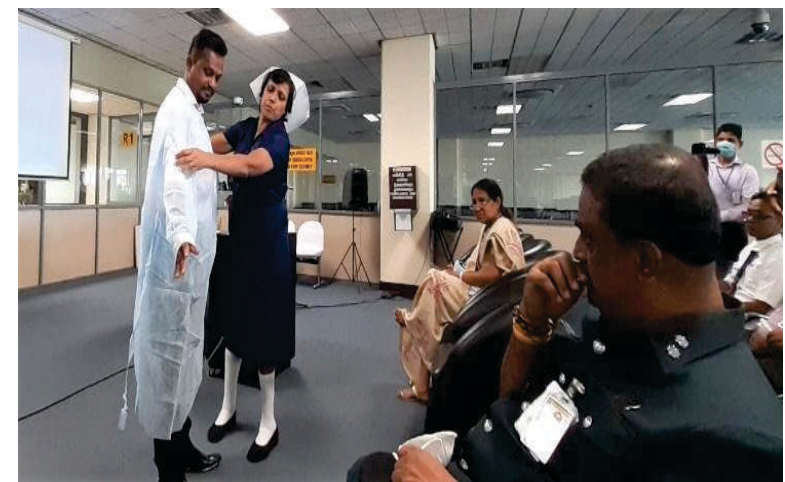

Figure 1: Awareness programmes conducted for the airport staff

b. Passenger screening though thermal scanners and Health Declaration Form

Thermal scanners were installed in strategic locations and temperature screening commenced on 23 January 2020 (Figure 2). During the period from 23 January to 19 March 2020, 699,443 passengers were screened for temperature and 44 persons were detected with fever. Passengers detected with fever and tested for COVID-19 had negative results. A health declaration form (HDF) was introduced on 26 January 2020 to obtain the details of passengers including travel history within the past 14 days, contact history with a patient or suspected patients and presence of symptoms of COVID-19.

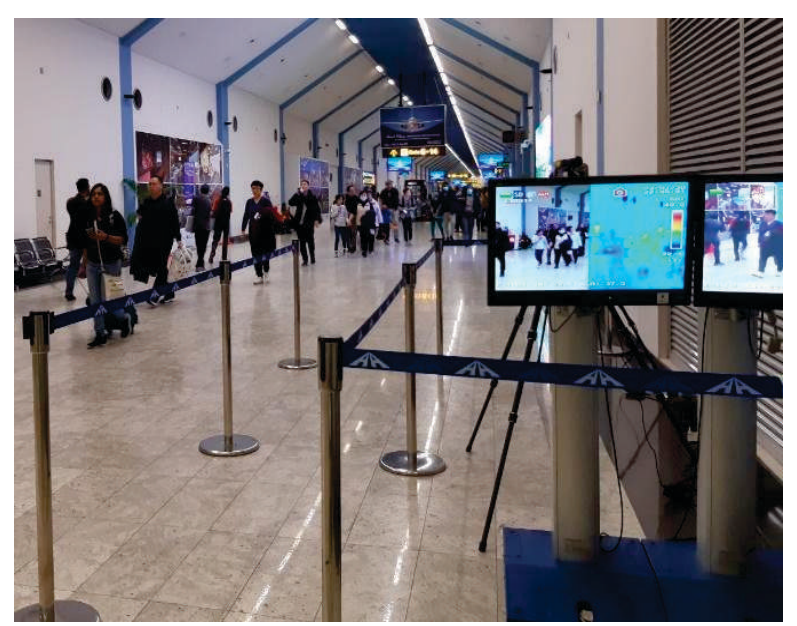

Figure 2: Thermal scanners installed at the airport

\section{c. Action taken for suspected patients}

If a passenger with elevated body temperature was detected or had a contact history or symptoms, the passenger was assessed by medical officers of the Airport Health Office and a decision was made whether to transfer the patient to designated hospital or not.

\section{d. Compiling data and community follow-up}

The details collected from the HDF were compiled by the Disaster Preparedness and Response Unit of the Ministry of Health and were transferred to the Epidemiology Unit within 24 hours. The Epidemiology Unit after assigning the medical officer of health $(\mathrm{MOH})$ area transferred the data to the respective area. The surveillance of passengers was done in the community by the area $\mathrm{MOH}$ and public health inspectors (PHIs) and home quarantined them for 14 days and the follow-up details were reported to the Epidemiology Unit.

\section{e. Travel restrictions}

In order to restrict the free entry from high risk countries, all types of electronic travel authorizations/ entry visas, landing endorsements, multiple entry visas were temporarily suspended. The foreign nationals from Iran, Italy and Republic of Korea were not allowed to enter Sri Lanka from 14 March 2020, and this travel ban was further expanded on 15 March 2020 to additional 13 countries, of which the majority included European countries where there was rapid community spread. Considering the rapid global spread, the airport was closed for incoming passenger flights on 19 March 2020.

\section{f. Quarantining of passengers and airline crew}

Considering the rapid community spread in some countries, the decision was taken to quarantine passengers from Italy, Iran and Republic of Korea at quarantine centres from 10 March 2020. Any passenger who arrived after the travel ban was sent for mandatory quarantine in quarantine centers. Sri Lankan Airlines crew were house quarantined for 14 days after the return flight. Crews of foreign airlines were housed in hotels with movement restrictions until the outbound flight. 


\section{g. Ports of sea}

In line with the public health measures taken at the airports, all disembarking crew members were required to submit the HDF and undergo temperature screening. Details of HDF were sent to the Epidemiology Unit.

A contingency plan was available for seaports and was activated. Discussions were held with key stakeholders. Awareness was done for staff of the seaports by the medical officers and public health inspectors. Evacuation drill was conducted at Colombo Port on 5 February 2020. Locations were identified to isolate suspected travelers. A Health Status Report (HSR) was developed to obtain advance passenger information. All vessels were required to submit the HSR 12-24 hours prior to arrival and medical officers after assessing the risk decided whether to give permission to berth or not.

Cruise ships calling to the Colombo port carried a large number of passengers. All passengers from cruise ships had to undergo temperature screening (Figure 3). Considering the high risk posed from a large number of passengers from different countries passenger disembarkation from cruise ships was stopped from 2 March 2020. From 19 March, all disembarkation from vessels were stopped. Only cargo operations were permitted.

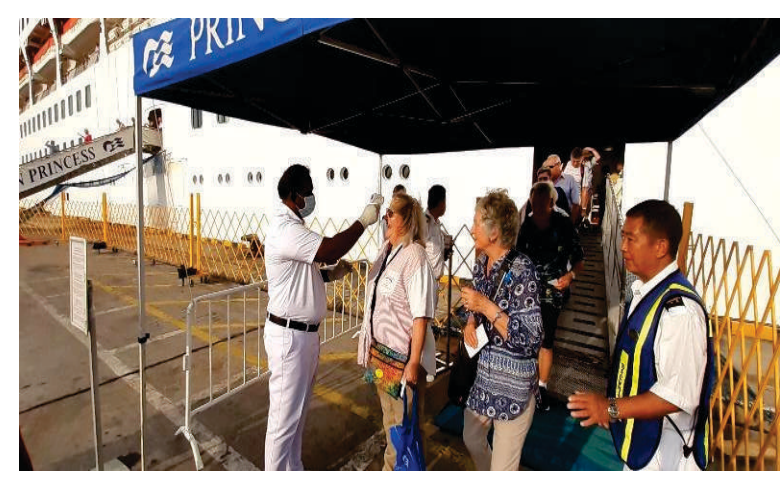

Figure 3: Temperature screening done of passengers arriving in cruise ships

\section{Lessons learnt}

- Sri Lanka had a rapid initial response at points of entry by initiating the screening process at an early stage of the epidemic even before it was declared as a PHIEC.

- The passenger data collection was supported by a well-established community surveillance system coordinated by the Epidemiology Unit.

- The capacity of the designated airport to respond to the rapidly spreading disease of this magnitude was not sufficient. This included space, staff and logistics.

- Since there were many stakeholders involved, it resulted in some gaps in coordination. Even though a public health contingency plan was available, the implementation of this plan was difficult due to poor awareness of the plan and lack of coordination.

- Lack of staff and logistic facilities resulted in congestion during peak hours.

- If the decision on travel ban was taken a little earlier, it may have had an impact on the number of imported cases.

- The benefit of temperature screening which is labour intensive should be reconsidered since the yield was 6 per 100,000 passengers and there were no COVID-19 positives among passengers detected with fever.

- Risk communication to the public should have been more coordinated among different stakeholders.

- Due to the fact that stringent measures were informed and taken in collaboration with the Ports Authority, good control over introduction of the disease was attained at the seaports.

\section{Author Declaration}

Author contributions: SMA drafted the manuscript. SDS and RPPK contributed to drafting the manuscript. HMRCS, TLCS and PP contributed to editing the manuscript. All authors read and approved the final manuscript. 


\section{References}

1. Al Jazeera. A timeline: how the new coronavirus spread. Available from: https://www. aljazeera.com/ news/2020/01/timeline-china-coronavirus-spread200126061554884.html.

2. Word Health Organization. Pneumonia of unknown cause - China. Available from: https:// www.who.int/ csr/don/05-january-2020-pneumonia-of-unkowncause-china/en/.

3. Jun She, Jinjun Jiang, Ling Ye, Lijuan Hu, Chunxue Bai, Yuanlin Song. 2019 novel coronavirus of pneumonia in Wuhan, China: emerging attack and management strategies. Clinical Translational Medicine 2020; 9: 19. DOI: 10.1186/s40169-02000271-z.

4. Zhu N, Zhang DY, Wang WL, et al. A novel coronavirus from patients with pneumonia in China, 2019. New England Journal of Medicine 2020; 382; 8. DOI: $10.1056 /$ nejmoa2001017.

5. Huang CL, Wang YM, Li XW, et al. Clinical features of patients infected with 2019 novel coronavirus in Wuhan, China. Lancet 2020; 395(10223): 497-506. DOI: 10.1016/s0140-6736(20)30183-5.
6. Sharon Begley. Once widely criticized, the Wuhan quarantine bought the world time to prepare for Covid-19. STAT. Available from: https://www. statnews.com/2020/02/21/coronavirus-wuhanquarantine-bought-world-time-to-prepare/.Acce ssed 21 February 2020.

7. Praveen Duddu. Coronavirus in Thailand: dealing with the 2019-nCoV (COVID-19) outbreak and impact. Pharmaceutical Technology. Available from: https://www. pharmaceutical-technology. com/ features/ coronavirus-affected-countriesthailand-measures-impact-tourism/.

8. WHO Regional Office for Europe. 2019-nCoV outbreak is an emergency of international concern. Available from: http://www. euro.who.int/en/healthtopics/health-emergencies/coronavirus-covid19/news/news /2020/01/2019-ncov-outbreak-is-anemer gency-of-international-concern.

9. World Health Organization. WHO Timeline COVID-19. Available from; https://www.who. int/news-room/detail/27-04-2020-who-timeline--covid-19. 